PORTARIAS

\title{
Divisão de Seleção e Aperfeiçoamento
}

\author{
Instruções Gerais a que se relere a Portaria n! 107, de março \\ de 1963
}

\section{DA INSCRIÇAO NOS CONCURSOS}

A abertura, a fixação do prazo e os locais de inscrição, para cada concurso, serão divulgados em edital publicado no Diário Oficial.

$\mathrm{O}$ pedido de inscrição constará do preenchimento de uma ficha, fornecida ao candidato nos locais de inscrição.

Juntamente com a ficha de inscrição, o candidato deverá apresentar duas cópias de fotografia, $3 \times 4 \mathrm{~cm}$, tirada de frente e sem chapéu, bem ccmo documentos que comprovem estar em dia com as obrigaçõeś militares e eleitorais.

A ficha de inscrição não será aceita sem que esteja devidamente preenchida. Igualmente, não será aceita a ficha que ap:esentar rasuras ou emendas.

$\mathrm{Se}$ as condições do concurso exigirem a apresentação de documento, o candidato deverá juntá-lo, para que o pedido de inscrição seja aceito.

O pedido de inscrição implicará a aceitação das normas estabelecidas nestas instruções, nas instruções especiais do concurso, bem como em qualquer out1o ato administrativo que as suplemente, modifique ou interprete.

Não será permitida, sob qualque: pretexto, a inscrição condicional.

O limite de idade, para efeito de inscrição em concurso, se houver, será fixado nas instruções especiais ao mesmo referentes. Em qualquer caso, entretanto será aceita a inscrição do candidato que seja ocupante de cargo ou função pública.

Nos têrmos do $\S 3^{\circ}$ do Art. 19 da Lei $\mathrm{n}^{\bullet} 1.711$, de 28 de outub $\circ$ de 1952 e do Art. 6 ${ }^{\circ}$ da Lei $n^{\circ} 4.054$, de 2 de abril de 1962, todo aquêle que ocupar, interinamente, cargo cujo provimento efetivo dependa de habilitação em concurso será nêle inscrito, ex officio, devendo comparecer a qualquer dos postos de inscrição do D.A.S.P., dentro do prazo fixado no edital de abertura das inscrições pa:a apresentar a documentação exigida nas instruções reguladoras. A aprovação da inscrição ex-officio dependerá da satisfação, por parte do interino, de tôdas as exigências contidas nestas instruções e nas que regularem o concurso respective.

Ultimados os trabalhos da insc-ição, cujo encerramento se efetuará no dia e hora prefixados no edital de abertura, será a matéria submetida à aprovação do Chefe da Seção competente.

Os candidatos dos Estados, cujos nomes constem das listas enviadas pelos postos, terão os pedidos de inscrição aceitos pela D.S.A., ficando a aprovação definitiva na depiendênçia do exame da documentação, a ser feito pela D.S.A. em qualquer fase da realização do concurso.

O candidato, mesmo habilitado, cuja inscrição fôr cancelada, terá tôdas as provas anuladas, sem direito a qualquer recurso administrativo.

Nos concursos que se realizarem nos Estados, será permitida a transferência de inscrição, devendo, porém, o candidato inte-essado solicitá-la ao Diretor da D.S.A., até cinco dias antes da realização da primeira prova ou parte.

O pedido de inscrição de candidatos residentes em localidades distantes dos postos de inscrição poderá ser feito por via postal, desde que registrado 
no D.C.T. dentro do prazo das inscrições.

O candidato que fizer, na ficha de insc:ição, declaração falsa ou inexata, terá sua inscrição cancelada e anulados todos os atos dela decurrentes.

Apurada falsidade nas declarações do candidato e cancelada a inscrição, não the será aceito, pelo prazo de dois anos, pedido de inscrição em concurso promovido pela D.A.S.P.

$\mathrm{O}$ candidato habilitado em concurso receberá certificado, que será expedido pela Divisão de Seleção e Aperfeiçoamento.

No Distrito Federal e nos Estados, os certificados só serão entregues contra apresentação, por parte do interessado, do titulo eleitoral e de documento que comprove estar em dia com as obrigações militares.

$\mathrm{O}$ candidato que não apresentar a documentação exigida perderá todos os direitos confe:idos pela classificação no concurso, sem que lhe caiba direito a qualquer recurso, ou indenização.

\section{DAS PROVAS E DO SEU JULGAMENTO}

Os concursos poderão ser de provas ou de provas e titulos.

A ordem de realização das provas será determinada pela D.S.A.

A organização e os programas das provas serão objeto das instruções de cada concurso. Essas instruções deverão fixar os minimos parciais ou globais para habilitação dos candidatos.

As provas dos concursos serão realizadas em dia, ho:a e local prefixados, com aviso público ou mediante têrmo de ciência, submetido à assinatura dos interessados.

Não haverá segunda chamada para nenhuma prova, importando a ausência do candidato na atribuiçăo de grau zero à prova a que tiver faltado e sua eliminação, de plano, do concurso.

O candidato deverá exibir o seu Cartão de Identificação para ingresso no local de cada prova, sob pena de ser considerado ausente.

O candidato que se recusar a prestar qualquer prova, ou que se retirar do recinto durante a realização da mesma, sem a devida autorização, fi- cará automàticamente eliminadọ do concurso.

Será excluido do concurso, por ato do Diretor da D.S.A., o candidato que se tornar culpado de incorreção ou descortesia para com qualquer dos examinadores, executores, seus auxiliares ou autoridades presentes. Idêntica penalidade será aplicada ao candidato que, durante a realização de qualquer prova, fôr surpreendido em comunicação com outro candidato verbalmente, por escrito ou por outra qualquer forma, bem assim utilizando-se de livros, notas ou impressos, salvo os expressamente permitidos.

Os candidatos elim:nados na forma do item anterior não poderão inscrever-se, em qualquer outro concurso, durante o prazo de dois anos, contados da data da eliminaçăo.

As provas de cada concu-so poderăo, sempre que necessário e a juizo da D.S.A., ser realizadas em dias sucessivos, ou no mesmo dia, ainda que sejam de caráter eliminatório.

Concluidos os trabalhos de realização de cada prova, observar-se-á, para perfeita garantia da objetividade do julgamento, o seguinte:

a) os talōes de identificação que acompanham os folhetos serão destacados, logo após a terminação de cada prova, e fica-ão em invólucros lacrados sob a guarda da Seção competente, até a conclusão do respectivo julgamento $e$

b) cada talăo receberá um número, repetido, para identificação posterior, no folheto do qual o talăo fôr destacado.

O critério de correção será fixado pelos examinadores ou pela D.S.A.

O julgamento das provas será feito segundo a quantidade e perfeição do trabalho apresentado pelo candidato.

A identificaçăo das provas será feita pùblicamente, em dia, local e hora prèviamente marcados em edital publicado na Seção I do Diário Oticial da Uniăo, ou mediante têrmo de ciência, submetido à assinatu'a dos interessados.

Nas provas que exigirem o emprêgo de aparelhos, máquinas, materiais ou 
equipamento especial, o examinador poderá determinar a eliminação imediata do candidato, desde que êste demonstre não possuir a necessária capacidade para úilizar-se dessas peças sem risco de danificá-las ou provocar acidentes.

E' permitido ao candidato ter vista das provas que prestou, para efeito de recurso, observadas as seguintes normas:

a) a vista de p:ovas aos cand:datos inscritos na localidade em que se processar a identificação das provas. sòmente será concedida no dia, hora e local designados pela D.S.A.;

b) áos candidatos inscritos em localidades diferentes daquela em que se processar a identificação das provas, será facultado o prazo de 30 dias que se: seguirem à data da identificação, para solicitar a vista das provas na Seçãa competente.

Divulgado o resultado de qualquer prova, o candidato dêle poderá recorrer, desde que o faça dentro das normas de urbanidade e em têrmos, observado o seguinte:

a) o recurso constará de petição dirigida ao Diretor da Divisão de Seleção e Aperfeiçoamento;

b) o recurso formulado pelo candidato que tiver tido vista de prova deverá, sob pena de indeferimento in limine, ser fundamentado e indicar, com precisão, as questões e os pontos a se:em objeto de revisão;

c) o candidato, inscrito por qualquer localidade, que tiver tido vista de prova, deverá apresentar o recurso até 2 dias depois dessa vista;

d) ao candidato inscrito em localidade onde não haja sido dada vista e que não pretenda ou não possa ver a prova, será facultado o prazo de 30 dias, contados a partir da data da identificação, para requerer, ao $\mathrm{Di}$ retor da D.S.A. do D.A.S.P., revisáo geral de sua prova, estando isento da obrigação de fundamentar o pedido;

e) os recursos relativos a provas oxais, p-ático-orais, e defesa de tese deverão ser apresentados, até 2 dias depois de conhecidos os respectivos resultados;

f) os recursos referentes a provas de titulos ou monografias deverão ser interpostos no prazo de dois dias após conhecimento dos respectivos resultados através de tê:mo de ciência, ou de 30 dias no caso de publicação no Diário Oficial sem aquêle têrmo de ciência.

Se aceitar o recurso, o Diretor da D.S.A. ordenará as diligências que achar necessárias.

O examinador ou a Seção competen te, depois de conhecer das razóes apresentadas pelo recorrente, fa:á a revisão geral ou parcial da prova e emitirá parecer, só podendo propor a alteração da nota atribuída anteriormente se ficar evidenciado que houve êrro de fato na aplicação do critério do julgamento.

O Diretor da D.S.A. poderá mandar proceder, ex-officio, pela Seção competente ou por examinadores especialmente designados, à revisão das provas ou à desidentificação das mesmas. para efeito do nôvo julgamento, desde que se verifique apuração inadequada de critério ou não sejam observadas as instruções e normas divulgadas pela D.S.A.

O candidato poderá ainda:

a) recorrer, ao Diretor-Geral do D.A.S.P., do despacho do Diretor da D.S.A., até trinta dias depois de sua publicação no Diário Oficial;

b) reclamar ao Diretor-Geral do D.A.S.P., por intermédio do Diretor da D.S.A., no prazo improrrogável de trinta dias consecutivos, a contar da data da publicação do resultado final do Diário Oficial, contra erros ou omissões no cálculo das médias finais ou na classificação.

Não serão apreciadas as reclamações que não forem apresentadas em têrmos convenientes ou não apontarem, com absoluta clareza, fatos e circunstâncias que a justifiquem e permitam pronta apuração.

Se ficar provado vicio, irregularidade insanável ou preterição de formalidade substancial, o concurso serâ anulado parcial ou totalmente. 


\section{OS EXAMINADORES}

Compete à D.S.A. a elaboração de questões, organização e correção de provas, no que poderá ser auxiliada po: pessoas estranhas, designadas pelo seu Diretor.

O Diretor-Geral do D.A.S.P. poderá designar examinadores, que executarão êsses trabalhos, com assistência da D.S.A. e sob a orientação do Diretor da mesma.

As Bancas Examinadoras, quando houver, serão constituidas por pessoas de reconhecida idoneidade moral e capacidade, designadas pelo Diretor-Geral do D.A.S.P., mediante proposta escrita do Diretor da D.S.A.

Cada Banca Examinadora poderá ter um presidente designado dentre seus membros pelo Dietor-Geral do D.A.S.P. mediante indicação do Diretor da D.S.A.

$\mathrm{Na}$ ausência eventual do presidente, assumirá a presidência dos trabalhos - examinador designado pelo Diretor da D.S.A.

As Bancas Examinadoras orientarse-ão pelas instruçães baixadas pela D.S.A. para cada concurso e, no que couber, por estas Instruções.

A fim de manter a necessária unidade de orientação, o Diretor da D.S.A. poderá designar um servidor que coordenará os trabalhos das Bancas Examinadoras.

No caso de impedimento de qualquer dos membros da Banca Examinadora, du:ante a realização do concurso, serão designados substitutọs.

\section{DA HABILITAÇÃO DOS CANDI- DATOS}

Os resultados finais serão publicados, obedecendo-se à ordem decrescente de pontos. Serão publicados, apenas, os resultados referentes aos candidatos habilitados.

Só serão considerados habilitados os candidatos que obtiverem, em cada caso, os graus ou resultados fixados nas Instruções do concurso.
Nos concursos cujas inscrições foram abertas em diferentes pontos do território nacional (Distrito Federal, Estados ou Territórios) a classificação final dos candidatos, para efeito de nomeação, obedecerá, salvo motivo relevante ou conveniência da administração, a juizo exclusivo do D.A.S.P., ao critério regional.

Os candidatos, classificados no Distrito Federal e nos Estados ou Territórios, poderão, ex-officio, ou mediante requerimento à Divisão de Classificação de Cargos do D.A.S.P., ser indicados à nomeação para cargos lotados em unidades da Federação diferentes daquelas em que se habilitarem. e nas quais, depois de nomeados todos os candidatos constantes da respectiva classificação final, restarem vagas que devam ser providas.

Nos concursos em cujas Instruções foren previstas seções várias pelas çuais os candidatos devam optar no ato da inscrição, a classificação final far-se-á em tantas séries quantas forem as seções previstas, de modo que as nomeações possam obedecer aos interêsses do serviço.

A homologação do concurso poderá ser parcelada, e não dependerá da solução de recursos interpostos, nem do prazo para reclamação contra o processamento dos trabalhos.

O candidato ou os candidatos que, visando a interêsses pessoais, lancem mão de falsas alegações e fatos inveridicos como motivo de embargo do processo seletivo serão, após apu:ação dos fatos, processados criminalmente e impedidos de se inscreverem em concursus realizados pela D.S.A. durante cinco anos.

\section{DISPOSIÇÕES GERAIS}

A nenhum candidato será dado alegar desconhecimento destas Instruções. bem como das Instruçõas do concurso em que se tenha inscrito.

Os concursos, sejam gerais ou especificos, serão válidos, por dois anos, a contar da data da publicação da homologação no Diário Oficial excetua- 
dos os casos em que as Instruções fixarem expressamente outro prazo.

Os prazos a que se referem o item anterior, a juizo exclusivo da D.A.S., poderão ser prorrogados ou revalidados.

As presentes Inst:uções entrarão em vigor na data da sua publicação no
Diário Oficial, passando os concursos, ora em realização, a reger-se por elas.

Os casos omissos serão submetidos à consideração do Diretor da Divisão de Seleção e Aperfeiçoamento.

Ficam revogadsa as disposições em contrário. 